\title{
Clearance of amyloid $\beta$-protein and its role in the spreading of Alzheimer's disease pathology
}

\author{
Dietmar R. Thal * \\ Laboratory of Neuropathology - Institute of Pathology, Center for Biomedical Research, University of UIm, UIm, Germany
}

Keywords: amyloid $\beta$-protein, tau-protein, perivascular drainage, propagation of protein aggregates, cellular clearance

\section{OPEN ACCESS}

Edited by:

Roxana Octavia Carare University of Southampton, UK

Reviewed by:

Lary C. Walker

Emory University, USA

*Correspondence:

Dietmar R. Thal, dietmar.thal@uni-ulm.de

Received: 26 January 2015 Paper pending published: 17 February 2015

Accepted: 22 February 2015

Published: 09 March 2015

Citation:

Thal DR (2015) Clearance of amyloid $\beta$-protein and its role in the spreading

of Alzheimer's disease pathology

Front. Aging Neurosci. 7:25

doi: 10.3389/fnagi.2015.00025
Amyloid $\beta$-protein $(\mathrm{A} \beta)$ containing amyloid plaques and abnormal phosphorylated $\tau$-protein containing neurofibrillary tangles (NFTs) are hallmark lesions of Alzheimer's disease. Both A $\beta$ plaques and NFTs show hierarchical patterns in which the areas of the brain are subsequently affected by A $\beta$ plaques and NFTs, respectively (Braak and Braak, 1991; Thal et al., 2002). A $\beta$ plaques start to develop in the neocortex (phase 1) and spread from there into allocortical regions (phase 2), diencephalon, basal forebrain and striatum (phase 3), midbrain and medulla oblongata (phase 4), and finally into the pons and the cerebellum (phase 5) (Thal et al., 2002). The first NFTs in the brain hemispheres are found in the transentorhinal cortex (stage I), then in the entorhinal cortex (stage II), the hippocampus (stage III), the temporal cortex (stage IV), further neocortical areas except the primary fields (stage $\mathrm{V}$ ), and, finally, also in primary cortical areas, such as the primary visual cortex (stage VI) (Braak and Braak, 1991). Axonal connections between subsequently affected brain regions suggest that $\mathrm{AD}$ pathology spreads along neuronal pathways (Thal et al., 2002; Braak and Del Tredici, 2011).

Insufficient clearance of $A \beta$ has been considered to play an essential role in the pathogenesis of $\mathrm{AD}$. Clearance mechanisms that contribute to $\mathrm{A} \beta$ elimination from brain are cellular enzymatic proteolysis in glial cells, neurons or in the extracellular space (Qiu et al., 1998; Yamaguchi et al., 1998; Iwata et al., 2000; Thal et al., 2000; Farris et al., 2003), transport through the bloodbrain barrier (Shibata et al., 2000; Ito et al., 2007), and perivascular drainage (Weller et al., 2008) (Figure 1A).

Here, I will discuss the potential impact of impaired $A \beta$ clearance on propagation mechanisms for $A \beta$ and $\tau$.

\section{Biophysical and Biochemical Prerequisites for $A \beta$ and $\tau$ Protein Aggregation}

Biophysically, protein aggregation takes place once a critical concentration of proteins has been passed. Fibril formation sets in after a concentration-dependent lag-phase, i.e., the time interval between passing a critical concentration and forming fibrils (Figure 1B) (Chirita et al., 2005). Within the lag-phase, assembly of proteins into non-fibrillar intermediates, i.e., oligomers of all sizes, precedes fibril formation (Thal et al., 2015). Proteins in general differ in their capability to aggregate, and their assembly can be further modulated by chaperones (Gething and Sambrook, 1992). Posttranslational modifications of proteins, such as N-terminal truncation and pyroglutamate formation, phosphorylation, or glycation increase the tendency of $A \beta$ or $\tau$ to form aggregates (Necula and Kuret, 2004; Schlenzig et al., 2009; Kumar et al., 2011). Seeds of preaggregated fibrils can reduce the lag-phase dramatically and trigger immediate aggregation (Figure 1B). 

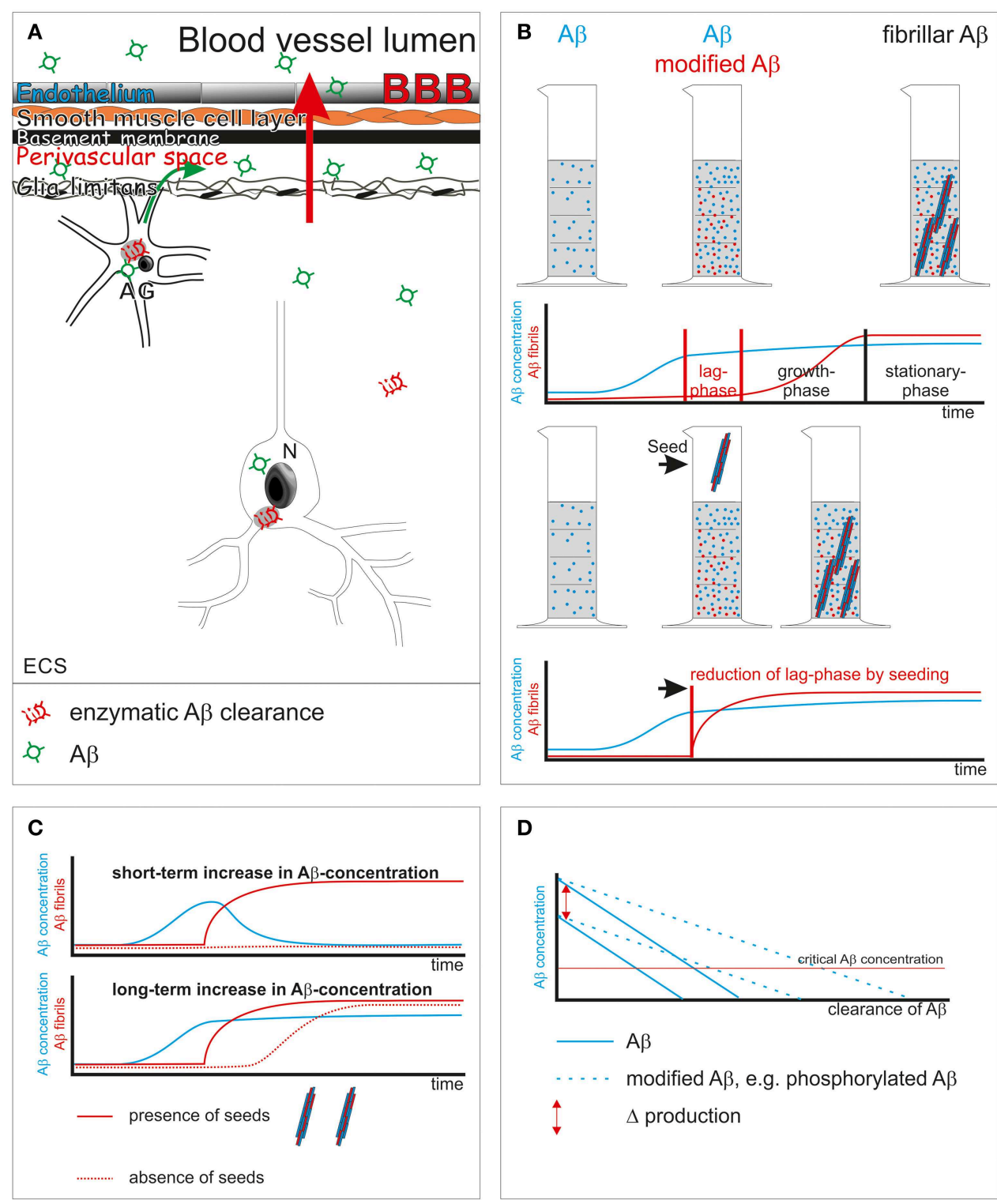

E Propagation of $A \beta$-seeds from region 1 to region 2

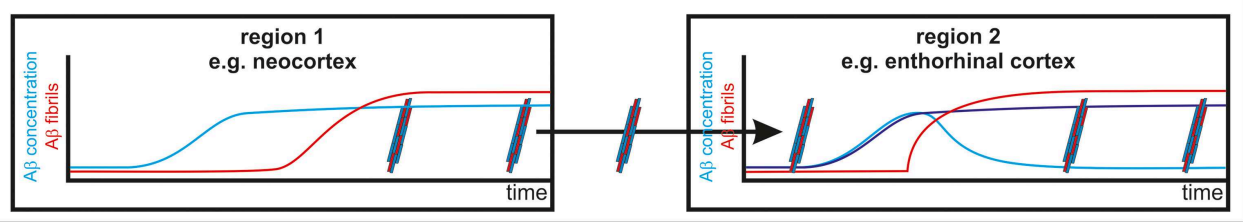

FIGURE 1 | Schematic representation of $A \beta$ clearance and

propagation. (A) $A \beta$ clearance mechanisms: enzymatic clearance within neurons $(\mathrm{N})$ and glial cells [here shown in the example is an astrocyte (AG)] or in the extracellular space (ECS) (Qiu et al., 1998; Yamaguchi et al., 1998; Iwata et al., 2000; Thal et al., 2000; Farris et al., 2003); transport through the blood-brain barrier (BBB) into the blood (red arrow) (Shibata et al., 2000; Ito et al., 2007); drainage into the perivascular space (green arrow) (Weller et al., 2008). (B) A $\beta$ aggregation into fibrils shows a lag-phase that is reduced by the presence of seeds (Thal et al., 2015). (C) Initiation of A $\beta$ fibril formation in the presence of seeds starts immediately after a critical concentration is passed even for a short period of time. In the absence of seeds a longer increase of $A \beta$ concentration may be necessary to pass the lag-phase for initiating $A \beta$ aggregation. (D) Influence of clearance rate, $A \beta$-production and its composition [presence of modified forms of $A \beta$ that are cleared less effectively than normal A (Russo et al., 2002; Kumar et al., 2012)] on a potentially critical concentration of $A \beta$ for disease progression. $\mathrm{N}$-terminal truncated, pyroglutamate-modified $A \beta$ is less soluble than non-modified full-length $A \beta$ (Schlenzig et al., 2009). In other words, this modification of $A \beta$ modified its critical concentration for aggregation. (E) Propagation of $A D$ pathology, e.g., $A \beta$ plaques, takes place when seeds of $A \beta$ are transported to a second primarily non-involved brain region. As soon as the concentration of $A \beta$ passes a critical level $A \beta$ aggregation and fibril formation takes place, leading to the deposition of $A \beta$ plaques in the secondarily affected brain region. 
In other words, a prerequisite for $A \beta$ and/or $\tau$ protein aggregation is either a sufficient concentration of $A \beta$ or $\tau$ over a period of time long enough to pass the respective lag-phase or the presence of preaggregated seeds to start aggregation as soon as the critical protein concentration has been reached.

\section{$A \beta$ Clearance Modulates Concentration and Onset of Fibril Formation of $A \beta$}

Sufficient $A \beta$ clearance is required to prevent an increase of the $A \beta$ concentration. In the absence of preaggregated $A \beta$ seeds a short-term increase of $A \beta$ concentration not exceeding the lag-phase may not start the aggregation process. Accordingly, a "long-term" elevation of $A \beta$ concentration is required to initiate the process of $A \beta$ aggregation under normal conditions (Figures 1B,C). As soon as preaggregated $A \beta$ seeds are present aggregation of $A \beta$ will be initiated once the critical $A \beta$ concentration has been passed as demonstrated in animal models for $\mathrm{A} \beta$ deposition (Meyer-Luehmann et al., 2006) (Figure 1C).

\section{Impairment of $A \beta$ Clearance by Modified Forms and/or $A \beta$ Intermediates}

Posttranslationally modified forms of $\mathrm{A} \beta$ are cleared less efficiently from the brain as shown for $\mathrm{N}$-terminal truncated and pyroglutamate-modified $A \beta$ and phosphorylated $A \beta$ (Russo et al., 2002; Kumar et al., 2012) (Figure 1D). Oligomeric A $\beta$ intermediates are stable and quite resistant to degeneration (Viola and Klein, 2015). Moreover, $A \beta$ oligomers alter proteasomal clearance (Cecarini et al., 2012). Accordingly, it is tempting to speculate that even low amounts of $A \beta$ intermediates and fibrils as well as posttranslational modifications of $A \beta$ foster disease progression not only by acting as seeds but also by their property of impairing physiological $A \beta$ clearance and, thereby, increasing $A \beta$ concentration.

\section{Spreading of A $\beta$ Pathology}

Spreading of $\mathrm{A} \beta$ pathology means that $\mathrm{A} \beta$ aggregation and deposition already took place at least in the neocortex and a second region becomes involved in this process. Preaggregated neocortical A $\beta$ may be transported into secondarily affected brain regions by glial cells or neurons or by diffusion (Guo and Lee, 2014; Thal et al., 2015). In the event that seeds prevail in a given brain region $A \beta$ aggregation will be initiated as soon as a critical concentration has been passed (Figure 1E). Given the prevalence of cortical $A \beta$ plaques (i.e., aggregated $A \beta$ ) in most elderly individuals (Braak et al., 2011) it is tempting to speculate that progression of $A \beta$ pathology into further brain regions can be triggered by insufficient local clearance and subsequently increased $A \beta$ levels and by seeding its aggregation. If so, continuously lowering $A \beta$ concentration to avoid even short-term increases might be effective in preventing propagation of $\mathrm{A} \beta$ pathology, similar to the inactivation of $A \beta$ seeds as shown for continuous $A \beta$ antibody treatment in $A \beta$-producing mice (Paganetti et al., 2013).

\section{$A \beta$ and $\tau$}

Animal experiments in $\tau$-transgenic mice have demonstrated that injecting $A \beta$ or crossbreeding these animals with $A \beta$ producing amyloid precursor protein transgenic mice accelerates and increases $\tau$-pathology (Gotz et al., 2001; Lewis et al., 2001). Moreover, anti-A $\beta$ antibody treatment reduced $\tau$-pathology in an $A \beta$ and $\tau$-pathology producing mouse model (Oddo et al., 2004). As such, it is tempting to speculate that there is crossseeding of $\tau$-pathology by $\mathrm{A} \beta$ aggregates in vivo similar as in vitro (Lasagna-Reeves et al., 2010). Arguments against relevant crossseeding of $A \beta$ and $\tau$ in the $A D$ brain may be (a) that $\tau$ aggregates are intracellular aggregates while $A \beta$ plaques are extracellular protein aggregates, and (b) A $\beta$ plaques develop first in the neocortex whereas NFTs are found in this part of the brain only in advanced stages of AD. However, $A \beta$ also occurs intracellularly (Gouras et al., 2000) and $\tau$ aggregates are transported through the extracellular space (Kfoury et al., 2012), indicating that an interaction of $\tau$ and $A \beta$ may be possible either intra- or extracellularly. Moreover, as discussed for $A \beta$, a sufficient protein concentration is essential for the initiation of protein aggregation. Accordingly, cross-seeding of $\tau$ by $A \beta$ cannot take place if there is not enough aggregation-prone $\tau$ protein even in the presence of huge amounts of $A \beta$ seeds. Such a constellation may apply for neocortical brain regions in early stages of AD. Therefore, it seems to be likely that cross-seeding of $A \beta$ and $\tau$ contributes to the development of $\mathrm{AD}$ and may be modulated by changing the clearance of $A \beta$. Cross-seeding of $A \beta$ and $\tau$ does not exclude the independent aggregation of $\tau$, as $\tau$-aggregates have been shown to trigger the initiation of $\tau$-pathology (Clavaguera et al., 2009).

\section{Conclusion}

The hypothesis that insufficient $A \beta$ clearance contributes to the development of $\mathrm{AD}$ does not contradict a major role of preaggregated $A \beta$ and/or $\tau$ seeds in the propagation of the disease. Moreover, improving $A \beta$ clearance, e.g., by enhancing its enzymatic degradation or vaccination strategies, may be capable of slowing down disease propagation given the relevance of $A \beta$ as a substrate for the protein aggregation process in $\mathrm{AD}$.

\section{Acknowledgments}

The author received support for his scientific projects by DFGgrant TH624/6-1 and Alzheimer Forschung Initiative grants $\# 10810,13803$. 


\section{References}

Braak, H., and Braak, E. (1991). Neuropathological stageing of Alzheimer-related changes. Acta Neuropathol. 82, 239-259. doi: 10.1007/BF00308809

Braak, H., and Del Tredici, K. (2011). Alzheimer's pathogenesis: is there neuronto-neuron propagation? Acta Neuropathol. 121, 589-595. doi: 10.1007/s00401011-0825-z

Braak, H., Thal, D. R., Ghebremedhin, E., and Del Tredici, K. (2011). Stages of the pathological process in Alzheimer's disease: age categories 1 year to 100 years. J. Neuropathol. Exp. Neurol. 70, 960-969. doi: 10.1097/NEN.0b013e31823 $2 \mathrm{a} 379$

Cecarini, V., Bonfili, L., Cuccioloni, M., Mozzicafreddo, M., Rossi, G., Buizza, L., et al. (2012). Crosstalk between the ubiquitin-proteasome system and autophagy in a human cellular model of Alzheimer's disease. Biochim. Biophys. Acta 1822, 1741-1751. doi: 10.1016/j.bbadis.2012.07.015

Chirita, C. N., Congdon, E. E., Yin, H., and Kuret, J. (2005). Triggers of fulllength tau aggregation: a role for partially folded intermediates. Biochemistry 44, 5862-5872. doi: 10.1021/bi0500123

Clavaguera, F., Bolmont, T., Crowther, R. A., Abramowski, D., Frank, S., Probst, A., et al. (2009). Transmission and spreading of tauopathy in transgenic mouse brain. Nat. Cell Biol. 11, 909-913. doi: 10.1038/ncb1901

Farris, W., Mansourian, S., Chang, Y., Lindsley, L., Eckman, E. A., Frosch, M. P., et al. (2003). Insulin-degrading enzyme regulates the levels of insulin, amyloid beta-protein, and the beta-amyloid precursor protein intracellular domain in vivo. Proc. Natl. Acad. Sci. U.S.A. 100, 4162-4167. doi: 10.1073/pnas. 0230450100

Gething, M. J., and Sambrook, J. (1992). Protein folding in the cell. Nature 355, 33-45. doi: 10.1038/355033a0

Gotz, J., Chen, F., Van Dorpe, J., and Nitsch, R. M. (2001). Formation of neurofibrillary tangles in P3011 tau transgenic mice induced by Abeta 42 fibrils. Science 293, 1491-1495. doi: 10.1126/science. 1062097

Gouras, G. K., Tsai, J., Naslund, J., Vincent, B., Edgar, M., Checler, F., et al. (2000). Intraneuronal Abeta 42 accumulation in human brain. Am. J. Pathol. 156, 15-20. doi: 10.1016/S0002-9440(10)64700-1

Guo, J. L., and Lee, V. M. (2014). Cell-to-cell transmission of pathogenic proteins in neurodegenerative diseases. Nat. Med. 20, 130-138. doi: 10.1038/ nm.3457

Ito, S., Ohtsuki, S., Kamiie, J., Nezu, Y., and Terasaki, T. (2007). Cerebral clearance of human amyloid-beta peptide (1-40) across the blood-brain barrier is reduced by self-aggregation and formation of low-density lipoprotein receptor-related protein-1 ligand complexes. J. Neurochem. 103, 2482-2490. doi: 10.1111/j.14714159.2007.04938.x

Iwata, N., Tsubuki, S., Takaki, Y., Watanabe, K., Sekiguchi, M., Hosoki, E., et al. (2000). Identification of the major Abeta1-42-degrading catabolic pathway in brain parenchyma: suppression leads to biochemical and pathological deposition. Nat. Med. 6, 143-150. doi: 10.1038/77399

Kfoury, N., Holmes, B. B., Jiang, H., Holtzman, D. M., and Diamond, M. I. (2012). Trans-cellular propagation of Tau aggregation by fibrillar species. J. Biol. Chem. 287, 19440-19451. doi: 10.1074/jbc.M112.346072

Kumar, S., Rezaei-Ghaleh, N., Terwel, D., Thal, D. R., Richard, M., Hoch, M., et al. (2011). Extracellular phosphorylation of the amyloid beta-peptide promotes formation of toxic aggregates during the pathogenesis of Alzheimer's disease. EMBO J. 30, 2255-2265. doi: 10.1038/emboj.2011.138

Kumar, S., Singh, S., Hinze, D., Josten, M., Sahl, H. G., Siepmann, M., et al. (2012). Phosphorylation of amyloid-beta peptide at serine 8 attenuates its clearance via insulin-degrading and angiotensin-converting enzymes. J. Biol. Chem. 287, 8641-8651. doi: 10.1074/jbc.M111.279133

Lasagna-Reeves, C. A., Castillo-Carranza, D. L., Guerrero-Muoz, M. J., Jackson, G. R., and Kayed, R. (2010). Preparation and characterization of neurotoxic tau oligomers. Biochemistry 49, 10039-10041. doi: 10.1021/bi1016233

Lewis, J., Dickson, D. W., Lin, W. L., Chisholm, L., Corral, A., Jones, G., et al. (2001). Enhanced neurofibrillary degeneration in transgenic mice expressing mutant tau and APP. Science 293, 1487-1491. doi: 10.1126/science. 1058189
Meyer-Luehmann, M., Coomaraswamy, J., Bolmont, T., Kaeser, S., Schaefer, C., Kilger, E., et al. (2006). Exogenous induction of cerebral beta-amyloidogenesis is governed by agent and host. Science 313, 1781-1784. doi: 10.1126/science. 1131864

Necula, M., and Kuret, J. (2004). Pseudophosphorylation and glycation of tau protein enhance but do not trigger fibrillization in vitro. J. Biol. Chem. 279, 49694-49703. doi: 10.1074/jbc.M405527200

Oddo, S., Billings, L., Kesslak, J. P., Cribbs, D. H., and Laferla, F. M. (2004). Abeta immunotherapy leads to clearance of early, but not late, hyperphosphorylated tau aggregates via the proteasome. Neuron 43, 321-332. doi: 10.1016/j.neuron.2004.07.003

Paganetti, P., Reichwald, J., Bleckmann, D., Abramowski, D., Ammaturo, D., Barske, C., et al. (2013). Transgenic expression of betal antibody in brain neurons impairs age-dependent amyloid deposition in APP23 mice. Neurobiol. Aging 34, 2866-2878. doi: 10.1016/j.neurobiolaging.2013.06.013

Qiu, W. Q., Walsh, D. M., Ye, Z., Vekrellis, K., Zhang, J., Podlisny, M. B., et al. (1998). Insulin-degrading enzyme regulates extracellular levels of amyloid beta-protein by degradation. J. Biol. Chem. 273, 32730-32738. doi: 10.1074/jbc.273.49.32730

Russo, C., Violani, E., Salis, S., Venezia, V., Dolcini, V., Damonte, G., et al. (2002). Pyroglutamate-modified amyloid beta-peptides-AbetaN3(pE)strongly affect cultured neuron and astrocyte survival. J. Neurochem. 82, 1480-1489. doi: 10.1046/j.1471-4159.2002.01107.x

Schlenzig, D., Manhart, S., Cinar, Y., Kleinschmidt, M., Hause, G., Willbold, D., et al. (2009). Pyroglutamate formation influences solubility and amyloidogenicity of amyloid peptides. Biochemistry 48, 7072-7078. doi: 10.1021/bi900818a

Shibata, M., Yamada, S., Kumar, S. R., Calero, M., Bading, J., Frangione, B., et al. (2000). Clearance of Alzheimer's amyloid-ss(1-40) peptide from brain by LDL receptor-related protein-1 at the blood-brain barrier. J. Clin. Invest. 106, 1489-1499. doi: 10.1172/JCI10498

Thal, D. R., Rüb, U., Orantes, M., and Braak, H. (2002). Phases of Abeta-deposition in the human brain and its relevance for the development of AD. Neurology 58 , 1791-1800. doi: 10.1212/WNL.58.12.1791

Thal, D. R., Schultz, C., Dehghani, F., Yamaguchi, H., Braak, H., and Braak, E. (2000). Amyloid beta-protein (Abeta)-containing astrocytes are located preferentially near N-terminal-truncated Abeta deposits in the human entorhinal cortex. Acta Neuropathol. 100, 608-617. doi: 10.1007/s004010 000242

Thal, D. R., Walter, J., Saido, T. C., and Fändrich, M. (2015). Neuropathology and biochemistry of Abeta and its aggregates in Alzheimer's disease. Acta Neuropathol. 129, 167-182. doi: 10.1007/s00401-014-1375-y

Viola, K. L., and Klein, W. L. (2015). Amyloid beta oligomers in Alzheimer's disease pathogenesis, treatment, and diagnosis. Acta Neuropathol. 129, 183-206. doi: 10.1007/s00401-015-1386-3

Weller, R. O., Subash, M., Preston, S. D., Mazanti, I., and Carare, R. O. (2008). Perivascular drainage of amyloid-beta peptides from the brain and its failure in cerebral amyloid angiopathy and Alzheimer's disease. Brain Pathol. 18, 253-266. doi: 10.1111/j.1750-3639.2008.00133.x

Yamaguchi, H., Sugihara, S., Ogawa, A., Saido, T. C., and Ihara, Y. (1998). Diffuse plaques associated with astroglial amyloid beta protein, possibly showing a disappearing stage of senile plaques. Acta Neuropathol. 95, 217-222. doi: $10.1007 / \mathrm{s} 004010050790$

Conflict of Interest Statement: The author discloses the following potential conflicts of interest: DRT received consultancies from Covance Laboratories (UK) and GE-Healthcare (UK), a speaker honorarium from GE-Healthcare (UK) and collaborated with Novartis Pharma Basel (Switzerland)

Copyright $\odot 2015$ Thal. This is an open-access article distributed under the terms of the Creative Commons Attribution License (CC BY). The use, distribution or reproduction in other forums is permitted, provided the original author(s) or licensor are credited and that the original publication in this journal is cited, in accordance with accepted academic practice. No use, distribution or reproduction is permitted which does not comply with these terms. 